\title{
Effect of kebar grass (Biophytum petersianum Klotzsch) leaf extract on the growth and morphological structure of aflatoxigenic Aspergillus flavus
}

\author{
$1,2,{ }^{*}$ Lisangan, M.M., ${ }^{2}$ Syarief, R., ${ }^{2,3}$ Rahayu, W.P. and ${ }^{4,5}$ Dharmaputra, O.S. \\ ${ }^{1}$ Faculty of Agricultural Technology, Papua University, Jl. Gunung Salju Amban Manokwari-98314, West \\ Papua-Indonesia \\ ${ }^{2}$ Faculty of Agricultural Engineering and Technology, IPB University, PO Box. 220, Bogor-16680, West \\ Java-Indonesia \\ ${ }^{3}$ Southeast Asia Food and Agriculture Science and Technology Center, IPB University, Bogor, West \\ Java-Indonesia \\ ${ }^{4}$ Faculty of Mathematics and Natural Sciences, IPB University, Bogor, West Java-Indonesia \\ ${ }^{5}$ Southeast Asian Regional Centre for Tropical Biology (SEAMEO BIOTROP), Bogor, West Java- \\ Indonesia
}

\author{
Article history: \\ Received: 26 March 2019 \\ Received in revised form: 13 \\ June2019 \\ Accepted: 15 June 2019 \\ Available Online: 24 July \\ 2019
}

Keywords:

Antifungal,

Aspergillus flavus,

Biophytum petersianum

Klotzsch,

Food model media,

Kebar grass

DOI:

https://doi.org/10.26656/fr.2017.4(1).129

\begin{abstract}
The objective of this study was to investigate the antifungal activity of kebar grass (Biophytum petersianum Klotzsch) extract (KGE) on the mycelial growth, conidiation and morphological structure of two types of aflatoxigenic fungus, which are Aspergillus flavus BCCF 0219 and A. flavus BIO 2236. They were isolated in the three types of model media, namely carbohydrate-enriched medium, fat-enriched medium and protein-enriched medium with five concentrations of $\operatorname{KGE}(12,14,16,18$, and $20 \mathrm{mg} / \mathrm{mL})$ on each media. The best extract concentration of that inhibits the growth of A. flavus BCCF 0219 was found in the carbohydrate-enriched medium (95.7\%), which was $12 \mathrm{mg} / \mathrm{mL}$, whereas at $A$. flavus BIO 2236 was found in the fat-enriched medium (100\%), which was $16 \mathrm{mg} / \mathrm{mL}$. Based on SEM observation results, it was found that the mechanisms involved in fungal growth inhibitory by the KGE were by morphological alterations of the hyphal development, and the collapse of the entire hyphae. These findings indicated that KGE as a potential natural antifungal agent, particularly against aflatoxigenic fungi.
\end{abstract}

\section{Introduction}

Kebar grass (Biophytum petersianum Klotzsch), belonging to the family Oxalidaceae, is a native plant of Kebar District, West Papua, Indonesia. The plant grows naturally and widespread all over the Kebar District (Santoso et al., 2007). This plant is also found in Southeast Asia and Africa, especially in Mali region. Mali community uses this plant for the treatment of wounds, inflammation, ulcers, malaria, and fever (Inngjerdingen et al., 2008). Papuan community, especially in Kebar District, often uses this plant as a fertility drug.

Several studies reported that kebar grass has potential as antibacterial, hypoglycemic agent, immunomodulatory agent, chemoprotective agent, hypocholesterolemic agent, apoptosis, antiinflammatory, antitumor and prostaglandin biosynthesis (Natarajan et al., 2010). Furthermore, the use of methanol extract of kebar grass can affect the expression of COX-2 (Guruvayoorappan and Kuttan, 2008) and stimulate immune system cells in mice (Inngjerdingen et al., 2008). Some phenolic components that affect the system COX-1/COX-2 also have been isolated by Bucar et al. (1998). Kebar grass extract also shows the effect of apoptosis on B16F-10 cells and is able to regulate NO production and cytokine-associated macrophages to tumor formation (Guruvayoorappan and Kuttan, 2007).

Although Natarajan et al. (2010) have reported the antibacterial activity of kebar grass, there have been no reports of the antifungal activity of grass kebar. During the storage period, fungal growth on foodstuffs can lead to an increase in moisture content and humidity of the storage material. In this condition, the damage occurs so fast that nitrogen source materials needed to grow will be reduced and fungi need to maintain his life by utilizing the carbon source in the material as a source of energy. This situation will take place of fungi by doing secondary metabolism that produces mycotoxins (Syarief et al., 2012). 
Fungal contamination and their mycotoxin production lead to $25-40 \%$ or even more post-harvest economic losses in developing countries. About 4.5 billion people in underdeveloped countries are exposed to mycotoxins (Murugan et al., 2013). Aflatoxins are mycotoxins produced by $A$. flavus and $A$. parasiticus that are hepatotoxic, mutagenic, teratogenic, and carcinogenic to humans and animals (Alberts et al., 2006). Besides harmful to human and animal health, aflatoxin contamination in food and feed also resulted in the loss of significant economic ranged from \$85-100 million in the USA (Alberts et al., 2009), so that contamination of aflatoxigenic fungi received worldwide attention (Sohaibani et al., 2011).

Type of substrates is a factor which determines aflatoxin content produced by aflatoxigenic A. flavus. Since it is difficult to completely avoid aflatoxin contamination, the technology needed to reduce aflatoxin contamination without affecting the flavor and nutritional value of food and safety. As foodstuff can consist of carbohydrate, fat and protein, therefore as a preliminary screening, it is necessary to investigate the effects of kebar grass in inhibiting the growth of aflatoxigenic A. flavus in food system model and the mechanism of the growth inhibition itself.

A preliminary study in our laboratory was conducted to select the type of extract that gave the best growth inhibition of $A$. flavus. In our preliminary study, we have examined the fungal growth inhibitory activity of six Kebar grass extracts (KGE): four extracts from single solvent extraction by using n-hexane, ethyl acetate, methanol, and water. The other two extracts were obtained from successively extracted from n-hexaneEtOAc-MeOH and n-hexane-EtOAc. The result showed that n-hexane-EtOAc-MeOH of KGE had the highest inhibition of A. flavus BCCF 0219 and A. flavus BIO 2236 growth. In this study, we further determined a minimum inhibitory concentration (MIC) of KGE against the growth of aflatoxigenic A. flavus and the mechanism involved. The chemical profile of $\mathrm{KGE}$ was also analyzed by using pyrolysis GC-MS.

\section{Materials and methods}

\subsection{Plant materials}

Kebar grass was collected from Kebar district, Manokwari county, West Papua province. Kebar grass was identified by the Indonesian Institute of Science (LIPI).

\subsection{Chemicals}

All solvents were of analytical grade purchased from JT. Baker, USA.

\subsection{Plant extracts preparation}

Kebar grass leaves were air-dried for about 14 days or until the colour turned into golden brown and they were easily broken. The leaves were then crushed into coarse powder using a blender. As much as $200 \mathrm{~g}$ powdered kebar grass was extracted by maceration ( $1 \mathrm{hr})$ method combined with sonification (30 mins) at room temperature using three kinds of organic solvent, i.e. nhexane, ethyl acetate, and methanol solvents, followed by Whatman No.1 paper filtration. Maceration was repeated for two times and the filtrate was collected. The remaining residue of the plant material was dried for 24 hrs and was extracted using ethyl acetate and methanol solvent sequentially in a similar manner. The filtrate was collected and dried with a rotary evaporator. The hexaneethyl acetate-methanol filtrate was called as HEM extract. Residual solvent in HEM extract was removed by nitrogen gas (Deng et al., 2011). The extract was then stored at $4^{\circ} \mathrm{C}$ before used for the analysis of chemical composition, antifungal activity and morphological changes of fungal structure.

\subsection{Fungal isolate}

Isolates of A. flavus BCCF 0219 and A. flavus BIO 2236 were obtained from the Research Institute for Veterinary Science (BBLITVET) and SEAMEO BIOTROP Culture Collections, respectively.

\subsection{Preparation of fungal conidia}

Fungal conidia were prepared using a method by Joseph et al. (2005) with a slight modification. Each fungal isolate was cultured in PDA (PDA; Oxoid, England) slant and incubated at $28^{\circ} \mathrm{C}$ for 5 days. The conidia were harvested by adding $10 \mathrm{~mL}$ of sterile distilled water and collected aseptically using a sterile inoculation loop. The conidial suspension was dissolved in Tween $80(0.5 \%)$ and centrifuged $(2000 \times \mathrm{x})$ at $28^{\circ} \mathrm{C}$ for 5 mins. Conidial concentration was calculated using a haemocytometer and adjusted to $10^{6} \mathrm{CFU} / \mathrm{mL}$. The suspension was used to test the activity of kebar grass extract in inhibiting the growth of $A$. flavus isolates.

\subsection{Preparation of food media model}

Food model media is a medium for growing fungus that is made to mimic the conditions of real food. In this study food model media was made by adding carbohydrates, proteins, and fats to the agar media in order to mimic carbohydrate-rich foods, protein-rich foods, and fat-rich foods. Carbohydrate-enriched medium was prepared by the addition of $30 \%(\mathrm{w} / \mathrm{v})$ glucose (E Merck, Germany) on Bacto Agar (Difco, USA) (Shih and Marth, 1974). 
Fat-enriched medium was prepared using a method of Riba et al. (2010). As much as $100 \mathrm{~g}$ of grated coconut flesh was homogenized using $300 \mathrm{~mL}$ of heat distilled water for 5 mins. The mixture was filtered using four layers of cheesecloth. The filter obtained was adjusted its $\mathrm{pH}$ into 7.0 using $2 \mathrm{~N} \mathrm{NaOH}$. Agar powder (Difco, USA) was added $(20 \mathrm{~g} / \mathrm{L})$. Both media were sterilized in an autoclave at $121^{\circ} \mathrm{C}$ for 15 mins.

Protein-enriched medium was prepared using a method of Mellon and Cotty (1998) with a slight modification. As much as 30\% (w/v) skim milk (Difco, USA) was added with bacto agar medium and sterilized in an autoclave at $121^{\circ} \mathrm{C}$ for 10 mins.

\subsection{Py-GC/MS analyses of kebar grass extract}

Samples of kebar grass polar extract were pyrolyzed by using a CDS Pyroprobe 2020iS connected on line to a gas chromatograph with a Shimadzu GC-MS mass detector (GCMS-QP2010). Samples were introduced into a quartz capillary tube in each experiment. The capillary was automatically introduced into the centre of a platinum resistor which heats up in an inert atmosphere. The products generated in pyrolysis were rapidly removed from the reaction zone (quartz capillary surrounded by the resistor) using a flow of helium, through a transfer line at the temperature of $280^{\circ} \mathrm{C}$ until introduced into the gas chromatograph provided with a mass spectrometry detector for analysis. Pyrolysis temperature was $400^{\circ} \mathrm{C}$. GC analysis was carried out using a Rtx-5MS fused silica capillary column (60 $\mathrm{m} \times 0.25 \mathrm{~mm} \times 0.25 \mu \mathrm{m})$. The column temperature was 50 $-280^{\circ} \mathrm{C}$. Helium was used as a carrier gas at a constant pressure of $100 \mathrm{kPa}$. Identification of different compounds obtained in this analysis was performed by using the Wiley 7 mass spectral library (Valdés et al., 2013).

\subsection{Antifungal activity of Kebar grass extract in food model media}

\subsubsection{Mycelial growth assay}

The effect of kebar grass extract on mycelial growth of A. flavus tested was conducted using Tian et al. (2011) methods. The concentrations of kebar grass extract added to food model media were $12,14,16,18$, and $20 \mathrm{mg} / \mathrm{mL}$. A total of $10 \mathrm{~mL}$ of medium containing extract was poured into the medium in Petri dish $(9 \mathrm{~cm}$ in diameter) and left until it was solid. Five microliters of conidial suspension of $A$. flavus isolate was inoculated on the surface of each test media and incubated at $28^{\circ} \mathrm{C}$ for 10 days. The diameter of the colony (in $\mathrm{mL}$ ) was observed every $24 \mathrm{hrs}$. Fungal cultured in food model media without kebar grass extract was used as the negative control. The inhibitory percentage was calculated using the following formula:

$$
(d c-d t) / d c \times 100 \%,
$$

Where $d c=$ diameter of control colony and $d t=$ diameter of fungal colony in treatment set

In this study, the concentration of extract giving $>90 \%$ of growth inhibitory activity was expressed as Minimum Inhibitory Concentration (MIC) and it was used in the subsequent test (Manso et al., 2013). Two replicates were used for each treatment combination, including the control.

\subsubsection{Sample preparation for scanning electron microscopy analysis}

A mycelial disk (2-mm diameter) was taken at the periphery of the colony grown on the cellophane disk placed on the model media with $0,1,1.5,2$ MIC with and without kebar grass polar extract after ten days of incubation. It was then dried at $60^{\circ} \mathrm{C}$ on a small glass slide $(1 \mathrm{~cm} \times 1 \mathrm{~cm})$. Samples were fixed in $2.5 \%$ glutaraldehyde for $30 \mathrm{mins}$ at room temperature. They were rinsed in distilled water (three times, 15 mins each). The specimens were then dehydrated in a graded ethanol series $(30,50,70 \%, 10$ mins for each ethanol dilution and $30 \mathrm{mins}$ in $100 \%$ ethanol). The samples were then coated with gold-palladium using an ion sputter-cutter (JEOL JFC 1100). The preparations were observed using a SEM Zeiss EVO 50 (Germany) (de Billerbeck et al., 2001).

\section{Results}

\subsection{Chemical composition of methanol extracts}

The chemical composition of kebar grass methanol extracts that extracted by graded extraction using hexane -ethyl acetate-methanol solvents is presented in Table 1 . A total of 64 components were identified using pyrolysis/gas chromatography/mass spectrometry (Py/ GC/MS), consist of a class of carboxylic acids (7.81\%), amines $(1.56 \%)$, phenolics $(26.56 \%)$, terpenes $(15.60 \%)$, alcohols (10.94\%), hydrocarbons compounds $(20.3 \%)$, benzene derivatives $(6.25 \%)$, carbohydrate derivatives (4.69\%), steroidal saponin $(1.56 \%)$, haloalkane $(1.56 \%)$, and sterols (3.13\%), 10 components were left unidentified.

\subsection{Fungal growth inhibition}

MIC values of kebar grass polar extract against isolates of A. flavus BCCF 0219 and A. flavus BIO 2236 are presented in Table 2. Inhibition of fungal growth was influenced by the concentration of extract given. The concentration of kebar grass polar extracts of three food model media affected on the delay of fungal growth. The 
Table 1. Chemical composition of kebar grass polar extract

\begin{tabular}{|c|c|c|}
\hline Compound & Group & $\% *$ \\
\hline Ammonium carbamate & Carboxylic acid & 1.42 \\
\hline Trimethylamine & Amine & 0.29 \\
\hline Izal & Phenol & 0.68 \\
\hline 1- Menthene & Terpene & 0.2 \\
\hline Acetic acid & Carboxylic acid & 0.77 \\
\hline 1-Limonene & Terpene & 2.35 \\
\hline 1,3-Cyclopentadien, 5,5-Dimethyl-2-Propyl- & Terpene & 0.11 \\
\hline 2,6-Dimethylstyrene & Benzene derivatives & 0.22 \\
\hline Guaiacol & Phenol & 0.81 \\
\hline Beta-Ocimene-X & Terpene & 0.14 \\
\hline 3,5,5-Trimethyl-2-cyclohexenone & Benzene derivatives & 0.1 \\
\hline 1,5,8-p-menthatriene & Terpene & 0.07 \\
\hline trans-p-Mentha-1(7),8-dien-2-ol & Terpene & 0.07 \\
\hline p-Ethylphenol & Phenol & 0.15 \\
\hline 2-Methoxy-4-methylphenol & Phenol & 0.13 \\
\hline Pyrocatechol & Phenol & 2.21 \\
\hline 2,3-Dihydro-benzofuran & Benzene derivatives & 0.39 \\
\hline 4-Cyclopentene-1,3-dione, 4-propyl- & Alicyclic hydrocarbons & 0.05 \\
\hline 3-Methoxy-pyrocatechol & Phenol & 0.14 \\
\hline p-Ethylguaiacol & Phenol & 0.3 \\
\hline Hydroquinone & Phenol & 0.33 \\
\hline 4-methyl catechol & Phenol & 0.74 \\
\hline 4-ethenyl-2-methoxy-phenol & Phenol & 0.17 \\
\hline 2,6-Dimethoxyphenol & Phenol & 0.41 \\
\hline p-Methoxyacetophenone & Phenol & 0.06 \\
\hline 1-N-Pentadecyl-Decahydronaphthalene & Alicyclic hydrocarbons & 0.12 \\
\hline Tetradecane & Aliphatic hydrocarbons & 0.1 \\
\hline 3,7,11-Tridecatrienenitrile, 4,8,12-trimethyl- & Terpene & 0.3 \\
\hline p-Hydroxyacetophenone & Phenol & 0.79 \\
\hline Pentadecane & Aliphatic hydrocarbons & 0.2 \\
\hline ar-Curcumene & Terpene & 0.07 \\
\hline trans-3-Oxabicyclo[5.3.0]decan-2-on, 9-Isopropyliden & Alicyclic hydrocarbons & 0.08 \\
\hline 1,6-Anhydro-beta-D-glucopyranose (Levoglucosan) & Carbohydrate derivatives & 1.74 \\
\hline Lauric acid & Carboxylic acid & 0.15 \\
\hline 2,3,5,8-Tetramethyl-decane & Aliphatic hydrocarbons & 0.4 \\
\hline 1,2,4-Cyclopentanetrione, 3-methyl-5-(1-oxopropyl)- & Alicyclic hydrocarbons & 0.14 \\
\hline 1,6-Anhydro-beta-D-glucofuranose & Carbohydrate derivatives & 0.19 \\
\hline Cyclopentaneethanol, 2-(hydroxymethyl)-beta,3-dimethyl- & Alcohol & 0.13 \\
\hline alpha-Sinensal & Terpene & 0.55 \\
\hline Hexahydrofarnesol & Alcohol & 0.27 \\
\hline 4,8-Dimethyl-1-nonanol & Alcohol & 0.31 \\
\hline Myristic acid & Carboxylic acid & 0.55 \\
\hline p-Benzylphenol & Phenol & 0.65 \\
\hline Neophytadiene & Terpene & 1.59 \\
\hline Cholestan-3-one, cyclic 1,2-ethanediyl acetal, (5. alpha)- & Steroidal saponin & 1.06 \\
\hline 1-Bromo-tetracosane & Haloalkanes & 0.53 \\
\hline Vitamin E & Phenol & 9.83 \\
\hline Alpha-Tocopherol-acetat & methylated phenol & 9.13 \\
\hline $6,10,14$-hexadecatrien-1-ol,3,7,11,15, tetramethyl & Alcohol & 2.64 \\
\hline Palmitic acid & Carboxylic acid & 4.58 \\
\hline n-Nonacosane & Aliphatic hydrocarbons & 2.38 \\
\hline n-Triacontane & Aliphatic hydrocarbons & 2.11 \\
\hline beta-Tocopherol & Phenol & 3.38 \\
\hline n-Tetratetracontane & Aliphatic hydrocarbons & 6.42 \\
\hline Cholestan-7-one, cyclic 1,2-ethanediyl acetal, (5. alpha)- & Benzene derivatives & 3.65 \\
\hline Stigmasta-5,22-dien-3-ol, acetate, (3.beta.22Z)- & Sterol & 0.98 \\
\hline Alpha-Tocopheryl-beta-D-mannosid & Carbohydrate derivatives & 7.55 \\
\hline Oleat-stigmast-5-en-3-ol & Sterol & 6.31 \\
\hline 2,10-Dodecadien-1-ol, 3,7,11-trimethyl-, (Z)- & Alcohol & 0.46 \\
\hline 1,30-Triacontanediol & Alcohol & 2.59 \\
\hline Stearaldehyde & Aliphatic hydrocarbons & 0.81 \\
\hline Solanesol & Alcohol & 3.77 \\
\hline 2,6,10,14,18,22-Tetracosahexaene, $2,6,10,15,19,23$-hexamethyl- & Aliphatic hydrocarbons & 2.25 \\
\hline 2-Hexadecanone & Aliphatic hydrocarbons & 0.36 \\
\hline Unknown (10 compounds) & & 8.57 \\
\hline Total & & 100 \\
\hline
\end{tabular}

*percentage of the content of each constituent in total extract 
higher concentration of the extract the longer fungal growth delayed. The longer lag phase of A. flavus BCCF 0219 isolate, i.e. up to $2 \times 24 \mathrm{hrs}$, was observed in carbohydrate-enriched media after being exposed by kebar grass extract, at concentrations 14 and $16 \mathrm{mg} / \mathrm{mL}$; lag phase was longer by the increase of concentration of the extract. The lag phase of isolate BIO 2236 in carbohydrate-enriched media after being exposed with kebar grass extract at a concentration of $12 \mathrm{mg} / \mathrm{mL}$ reached $2 \times 24 \mathrm{hrs}$ and the lag phase was extended by the increase of concentration of the extract. Kebar grass polar extract with concentration of $14 \mathrm{mg} / \mathrm{mL}$ in fatenriched media extended the lag phase of isolates of $A$. flavus BCCF 0219 and A. flavus BIO 2236 up to $3 \times 24$ hours and 1x24 hours, respectively. Slow growth of $A$. flavus BIO 2236 isolate was observed after $2 \times 24 \mathrm{hrs}$; and when the concentration of kebar grass extract was increased the lag phase of $A$. flavus isolate was getting longer. The similar pattern was also shown by isolates of A. flavus BCCF 0219 and A. flavus BIO 2236 in proteinenriched media with the addition of kebar grass extract. The extract at concentrations of 12 and $14 \mathrm{mg} / \mathrm{mL}$ extended the lag phase of isolate A. flavus BCCF 0219 up to $1 \times 24 \mathrm{hrs}$, while the extract concentration of 12 $\mathrm{mg} / \mathrm{mL}$ extended the lag phase of $A$. flavus BIO 2236 isolate up to $1 \times 24 \mathrm{hrs}$. Again, by increasing the extract concentration, the longer the lag phase of both isolates.

Table 2. MIC and MFC value of kebar grass polar extract of isolates A. flavus BCCF 0219 and A. flavus BIO 2236

\begin{tabular}{clc}
\hline Type of media model & \multicolumn{1}{c}{ Isolate } & MIC $(\mathrm{mg} / \mathrm{mL})$ \\
\hline \multirow{2}{*}{ Carbohydrate } & A. flavus BCCF 0219 & 12 \\
& A. flavus BIO 2236 & 12 \\
Fat & A. flavus BCCF 0219 & 14 \\
& A. flavus BIO 2236 & 16 \\
Protein & A.flavus BCCF 0219 & 14 \\
& A.flavus BIO 2236 & 16 \\
Positive control & A.flavus BCCF 0219 & 5 \\
(ketoconazole) & A.flavus BIO 2236 & 5 \\
\hline
\end{tabular}

3.3 Conidial production and SEM Observation of fungal structure

MIC values determined in the previous stage were used as the basis for assessing the influence of kebar grass methanol extracts against conidial production and fungal structure. Concentrations of kebar grass extract used for this test were 0, 1, 1.5, 2 MIC. Kebar grass methanol extract at concentration of 1 MIC inhibited the production of conidia during 10 days of incubation. On carbohydrate-enriched media mycelium growth of $A$. flavus BCCF 0219 isolate was very thin and the conidiation occurred within $7 \times 24$ hrs incubation with a few conidial productions; while on the carbohydrateenriched media with kebar grass extract, growth of $A$. flavus BCCF 0219 isolate did not occur. The growth of
A. flavus BCCF 0219 isolate on fat-enriched media without kebar grass extract was fast, had compact colony and its conidiation occurred at $1 \times 24$ hrs incubation with abundant conidial production. The growth of A. flavus isolates on media with kebar grass extract was slow and failed to form conidia. The growth of A. flavus BCCF 0219 isolate on protein-enriched media without kebar grass extract was fast and showed a uniform colony, and conidiation occurred after 1 × 24 hrs incubation with abundant conidial production. Moreover, growth of $A$. flavus BCCF 0219 isolate on protein-enriched media with kebar grass extract showed slow growth and conidiation occurred at $10 \times 24 \mathrm{hrs}$ incubation with very few conidial productions.

Kebar grass methanol extract with a concentration based on MIC values obtained in the previous stage not only inhibited the growth of $A$. flavus isolates but also inhibited conidiation. On carbohydrate-enriched media, the growth of $A$. flavus BIO 2236 isolate was fast but with a very thin mycelium and the conidiation occurred within $8 \times 24$ hrs incubation with abundant conidial production and sclerotium was not formed. On carbohydrate-enriched media with kebar grass extract, growth of BIO 2236 isolate was slow and conidiation did not occur. Isolate of BIO 2236 inoculated on fat-enriched media without kebar grass extract showed very rapid growth and the conidiation occurred after 1 x $24 \mathrm{hrs}$ incubation with abundant conidial production and its sclerotium was formed at $3 \times 24 \mathrm{hrs}$ incubation. Meanwhile, on fat-enriched media was added with extract of kebar grass the fungal growth was slowly and conidiation did not occur. Isolate of BIO 2236 grown on protein-enriched media without kebar grass extract showed rapid growth and the conidiation occurred at $2 \mathrm{x}$ $24 \mathrm{hrs}$ incubation and sclerotium formation began at $4 \mathrm{x}$ $24 \mathrm{hrs}$ incubation, whereas in protein-enriched media with kebar grass extract, the isolate growth was slow and failed to form conidia.

Observation on fungal morphological structure using SEM is shown in Figures 1-5. Kebar grass extract with concentration of $1 \mathrm{MIC}$ on carbohydrate-enriched media resulting growth inhibitory of BCCF 0219 isolate up to $100 \%$. Hyphal structure of BCCF 0219 isolate on fatenriched media with kebar grass extract was thin and diameter size became smaller than the control (Figure 1b), whereas the conidia were not formed (Figure 1d). On protein-enriched media, fungal hyphae structure became thinner than control, hyphae was wound (Figure $2 \mathrm{~b}$ ) and the size of the conidia was also smaller than the control (Figure 2d).

Morphological changes in the hyphal of BIO 2236 isolate grown on carbohydrate-enriched media with 

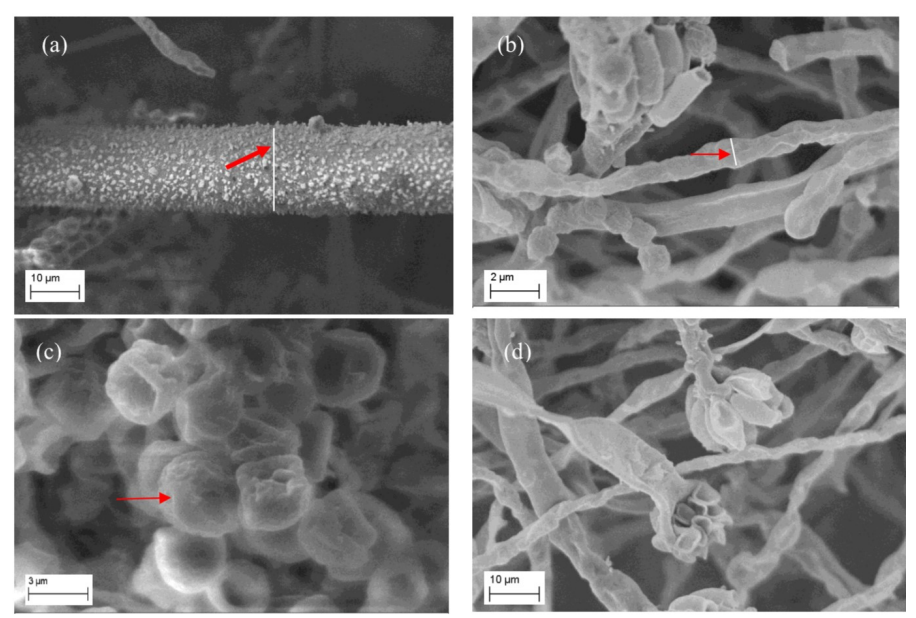

Figure 1. Structure of A. flavus BCCF 0219 on fat-enriched media (a) Hyphal structure of control, mag. 1000x, $d=22.11$ $\mu \mathrm{m}$, (b) Hyphal structure treated using $1 \mathrm{MIC}\left(14 \mathrm{mg} \mathrm{mL}^{-1}\right)$, mag. $2000 \mathrm{x}, \mathrm{d}=3.23 \mu \mathrm{m}$, (c) Conidial structure of control, mag. $5000 \mathrm{x}, \mathrm{d}=4.3 \mu \mathrm{m}$, (d) Conidial structure treated using 1 MIC (14 mg mL $\left.{ }^{-1}\right)$, mag. 1500x
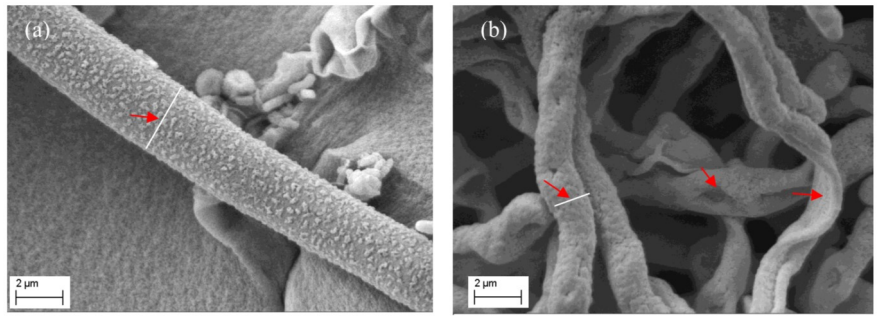

Figure 3. Hyphal structure of A. flavus BIO 2236 on carbohydrate-enriched media (a) Hyphal structure of control, mag. 2000x, d=8.85 $\mu \mathrm{m}$ and (b) Hyphal structure treated using 1 MIC (12 mg mL-1), mag. 3000x, d=2.64 $\mu \mathrm{m}$
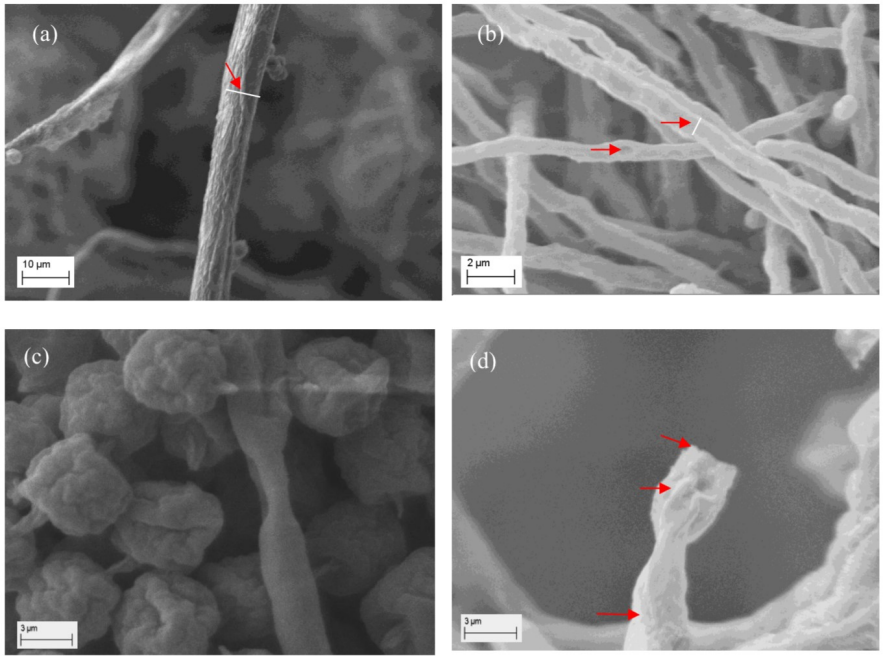

Figure 5. Structure of $A$. flavus BIO 2236 on protein-enriched media (a) Hyphal structure of control, mag. 1000x, d=8.96 $\mu \mathrm{m}$, (b) Hyphal structure treated using $1 \mathrm{MIC}(16 \mathrm{mg} \mathrm{mL}-1)$, mag. $3000 \mathrm{x}, \mathrm{d}=1.86 \mu \mathrm{m}$ (c) Conidial structure of control, mag. $5000 x$, (d) Vesicle, phialide and metulae structure treated using 1 MIC (16 mg mL-1), mag. 5000x.

kebar grass extract also occurred; folding hyphae was formed, and minor injuries occurred on the surface of the hyphae (Figure $3 \mathrm{~b}$ ) while the conidia were not formed. Isolate of A. flavus BIO 2236 inoculated on fat-enriched media with kebar grass extract also suffered damage on
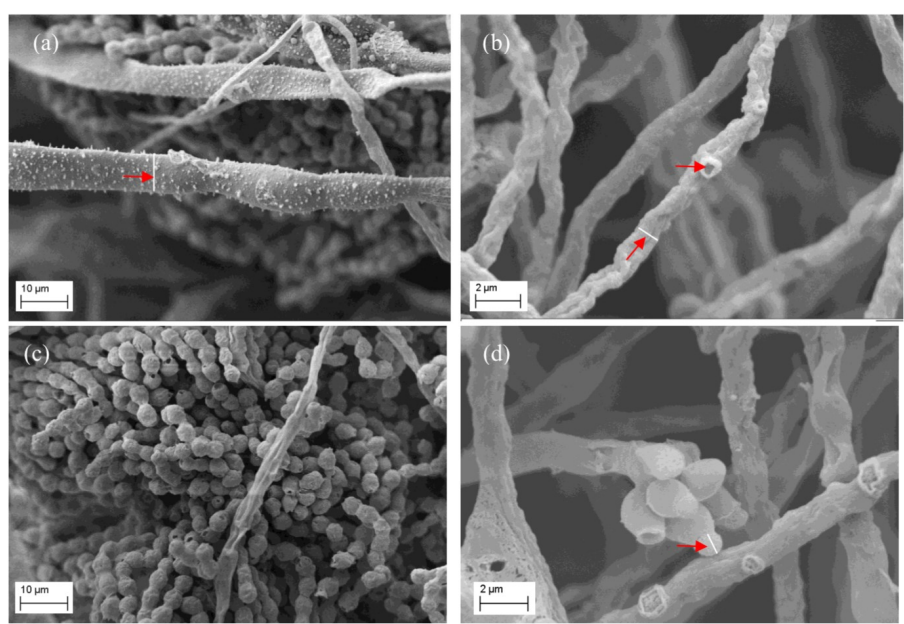

Figure 2. Structure of A. flavus BCCF 0219 on proteinenriched media (a) Hyphal structure of control, mag. 1000x, $\mathrm{d}=9.72 \mu \mathrm{m}$ (b) Hyphal structure treated using $1 \mathrm{MIC}(14 \mathrm{mg}$ $\mathrm{mL}-1$ ), mag. $2000 \mathrm{x}, \mathrm{d}=3.21 \mu \mathrm{m}$, (c) Conidial structure of control, mag. $1000 \mathrm{x}, \mathrm{d}=5.2 \mu \mathrm{m}$ (d) Conidial structure treated using $1 \mathrm{MIC}$ (14 mg mL-1), mag. 2500x, d= $2.5 \mu \mathrm{m}$
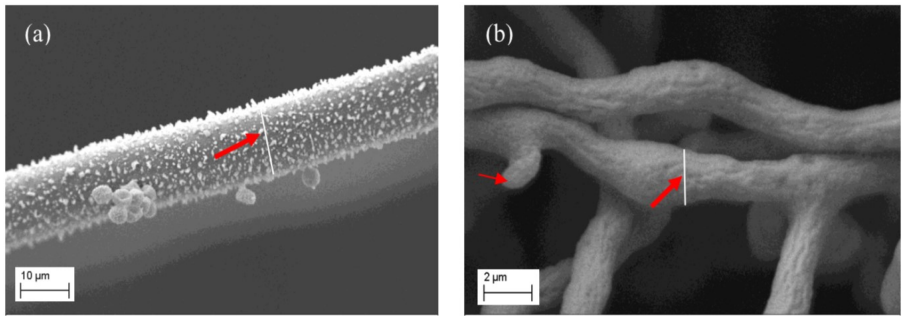

Figure 4. Hyphal structure of A. flavus BIO 2236 on fatenriched media (a) control, mag. 1000x, $d=17.95 \mu \mathrm{m}$ and (b) 1 MIC (16 mg mL-1), mag. 5000x, d=1.27 $\mu \mathrm{m}$

the hyphal, such as a wound on the hyphal surfaces, and formed short branches of hyphae (Figure $4 b$ ), as well as did not form any conidia. Isolate of BIO 2236 inoculated on protein-enriched media with kebar grass extract also suffered damage on the hyphae; it had rough and wound on hyphal surfaces (Figure 5b), short branches of hyphae were formed and failed to form conidia, whereas vesicle, phialide and metulae also folded (Figure 5d).

\section{Discussion}

Kebar grass polar extract inhibited the growth of $A$. flavus BCCF 0219 and BIO 2236 in a dosage response manner. In the present study, the polar extract of kebar grass leaf was reported as a potent inhibitor of A. flavus growth in vitro. The extract showed a fungistatic activity toward the fungus at all concentrations used which were significant for the concentrations $\geq 12 \mathrm{mg} / \mathrm{mL}$ compared to control of all food model media. Some other studies reported the activity of essential oil against conidiation; thus this result can be evaluated as the first report. The inhibitory effect of EOs against conidiation of different fungi has been previously reported (Gandomi et al., 2009). Tataoui-Elaraki et al. (1993) studied the effect of three Moroccan EOs on fungal asexual reproduction stages including conidial production and reported that 
the partial inhibition of conidial production could be attributed to mycelial destruction or inhibition of fungal growth. Mahanta et al. (2007) suggested that the impact of Cymbopogon citrates L. essential oil on conidiation may reflect the effects of volatile compounds emitted by the oil on the surface of developing mycelia, and thus the stage to support conidial production involved in the switch from vegetative to reproductive development. Reduction of conidial production could limit the spread of pathogens by lowering the conidia load in the storage atmosphere and on surfaces (Tzortzakis and Economakis, 2007).

There are few reports on the growth inhibitory potential of kebar grass extract against bacteria and no report on the effect of plant extract on fungal especially against $A$. flavus growth and its effect on fungal morphological structure. Some researchers reported antibacterial activity of the methanolic extract of whole part of kebar grass against different pathogenic and medically important bacteria (Natarajan et al., 2010).

We reported here for the first time the inhibition of fungal growth and conidial production of $A$. flavus which was exposed to different concentrations of kebar grass extract in relation to morphological alterations in fungal compartments. From the SEM observations, it was shown that hyphae of $A$. flavus treated with 1 MIC of the kebar grass extract was entirely collapsed and folded with the formation of short branches and undifferentiated tips. Morphological structure changes of fungal hyphae have been reported for A. flavus hyphae treated with Cymbopogon citratus oil (Helal et al., 2007) and Matricaria chamomilla L. flower essential oil (Tolouee et al., 2010).

An interesting observation in bioassays was the inhibition of conidial production in relation to fungal growth inhibition. Marked reduction in A. flavus conidial production by kebar grass extract reported in the present study might be a consequence of retardation in vegetative growth development through affecting the normal fungal branching pattern. In these results, with kebar grass extract, completely squashed and severely collapsed hyphae were recorded, which results in flattening and ultimately death of hyphae. The hyphae showed damage, loss of the cell wall integrity and rigidity, and the cell wall was folded. These observations indicate that the mode of antifungal activity of kebar grass extract, a result of the attack on the cell wall. Such effects induced by kebar grass extract may be related to the interference of extract bioactive components with enzymatic reactions of wall synthesis, which affects fungal morphogenesis and growth. Zambonelli et al. (1996) reported that fungal growth inhibition can be associated with degeneration of fungal hyphae after treatment with Thymus vulgaris essential oil. Our observations are in agreement with the above reports.

Selected compounds of kebar grass polar extract including phenolics (26.56\%), terpenes (15.60\%), alcohols (10.94\%), steroidal saponin (1.56\%) also reported has antifungal activity (Marei et al., 2012). To the best of the author knowledge, this is the first study to establish the chemical composition of leaf extract and antifungal activity of kebar grass. Lin and Wang (2003) reported that kebar grass also have biflavon (cupressuflavone and amentoflavone), flavonoid (luteolin 7-methyl ether, isoorientin, 3'-methoxyluteolin 7-O-glucoside), 4-caffeoylquinic acid and 5caffeoylquinic acid. Other study reported that there is a relationship between the chemical structures of the most abundant compounds in the tested oil and the antimicrobial activity. The extract rich in phenolic compounds are widely reported to possess high levels of antimicrobial activity (Skočibušić et al., 2006). Since the active antimicrobial compounds of plant extract are phenolics and terpenes, it seems reasonable that their mode of action might be similar to that of other phenolic compounds. Most of the studies on the mechanism of phenolic compounds focused on their effects on cellular membranes, altering its function and in some instances structure, causing swelling and increasing its permeability. A consistent observation is an increase in $\mathrm{K}^{+}$and often cytoplasmic content effluxes from cells in response to the antimicrobial challenge. These effects may develop as a result of membrane depolarization by altered ion transport or through changes in membrane structure, inhibition of energy (ATP) generation by interference with glucose uptake or inhibition of enzymes involved in oxidative or substrate level phosphorylation. Increases in cytoplasmic membrane permeability appear to be a consequence of the loss of the cellular $\mathrm{pH}$ gradient, decreased ATP levels, and loss of the proton motive force, which lead to cell death. Other mechanisms for the antimicrobial activity of simple phenolic compounds have been proposed to include enzyme inhibition by the oxidized compounds, possibly through reaction with sulfhydryl groups or through more non-specific interactions with proteins. More complex natural phenolic compounds such as quinones, flavones, flavonoids and flavanols exert their antimicrobial activity by complexing irreversibly with nucleophilic amino acids in proteins leading to inactivation of the protein and loss of function. The most probable targets in microbial cells are surface exposed adhesions, cell wall polypeptides, and membrane-bound enzymes (Samapundo et al., 2007). In addition, aflatoxin inhibitory effect of phenolic compounds through the mediation of oxidative stress levels in the fungi is also 
reported by Kim et al. (2006). Kim et al. (2006) have reported that growth inhibition of A. flavus by the phenolics salicylic acid, thymol, vanillyl acetone, vanillin and cinnamic acid is via targeting the mitochondrial oxidative stress defence system. Since the mitochondria are responsible for providing acetyl-CoA, a main precursor for AF biosynthesis, disruption of mitochondrial respiration chain may account in part for the inhibitory effects of antifungal phenolics on aflatoxin production. Hence, these plant extract rich in phenolics compound could be used as markers for the elucidation of antioxidant-based inhibition of aflatoxin biosynthesis. The antimicrobial properties of alcohols were known to increase with molecular weight. It is also evident that terpene alcohols such as trans-p-Mentha-1(7),8-dien-2ol, solanesol, 1-limonene exhibit strong antimicrobial activity, especially pronounced on whole cells, while hydrocarbon derivatives possess lower antifungal properties, as their low water solubility limits their diffusion through the medium (Prakash et al., 2012). The extract rich in saponin compounds is reported to have antimicrobial activity too. It is known that saponins change the membrane permeability leading to the rupture of the cell (Brusotti et al., 2013). These observations suggested that the antifungal effect of kebar grass leaf extract is probably due to the individual or synergistic effect of the secondary metabolites present in the extract.

\section{Conclusion}

A HEM extract of kebar grass possesses fungitoxic activities in inhibiting the growth of aflatoxigenic $A$. flavus, leading to irreversible deleterious morphological alterations and thus, it is worth exploiting for the bio management of aflatoxigenic A. flavus. The results of this study suggested the possibility to use HEM extract of kebar grass leaf as a natural preservative since it possesses strong antifungal activity. Further research regarding its application in the food system is needed to obtain information regarding the practical effectiveness of extract to prevent the growth of foodborne and spoiling microbes under the specific application conditions.

\section{Conflict of Interest}

Authors declare no conflict of interest.

\section{Acknowledgements}

This research was supported by the Indonesia Ministry of Higher Education.

\section{References}

Alberts, J.F., Engelbrecht, Y., Steyn, P.S., Holzapfel,
W.H. and van Zyl, W.H. (2006). Biological degradation of aflatoxin B1 by Rhodococcus erythropolis cultures. International Journal of Food Microbiology, 109(1-2), 121 - 126. https:// doi.org/10.1016/j.ijfoodmicro.2006.01.019

Alberts, J.F., Gelderblom, W.C.A., Botha, A. and van Zyl, W.H. (2009). Degradation of aflatoxin B1 by fungal laccase enzymes. International Journal of Food Microbiology, 135(1), 47-52. https:// doi.org/10.1016/j.ijfoodmicro.2009.07.022

Brusotti, G., Tosi, S., Tava, A., Picco, A.M., Grisoli, P., Cesari, I. and Caccialanza, G. (2013). Antimicrobial and phytochemical properties of stem bark extracts from Piptadeniastrum africanum (Hook f.) Brenan. Industrial Crops and Products, 43(1), 612-616. https://doi.org/10.1016/j.indcrop.2012.07.068

Bucar, F., Jachak, S.M., Noreem, Y., Kartnig, T., Perera, P., Bohlin, L. and Schubert-Zsilavecz, M. (1998). Amentoflavone from Biophytum sensitivum and its effect on COX-1/COX-2 catalysed prostaglandin biosynthesis. Planta Medica, 64(4), 373-374. https:// doi.org/10.1055/s-2006-957455

de Billerbeck, V.G., Roques, C.G., Bessière, J.M., Fonvieille, J.L. and Dargent, R. (2001). Effects of Cymbopogon nardus (L.) W. Watson essential oil on the growth and morphogenesis of Aspergillus niger. Canadian Journal of Microbiology, 47(1), 9-17. https://doi.org/10.1139/cjm-47-1-9

Gandomi, H., Misaghi, A., Basti, A.A., Bokaei, S., Khosravi, A., Abbasifar, A. and Javan, A.J. (2009). Effect of Zataria multiflora Boiss. essential oil on growth and aflatoxin formation by Aspergillus flavus in culture media and cheese. Food and Chemical Toxicology, 47(10), 2397-2400. https:// doi.org/10.1016/j.fct.2009.05.024

Guruvayoorappan, C. and Kuttan, G. (2007). Immunomodulatory and antitumor activity of Biophytum sensitivum extract. Asian Pacific Journal of Cancer Prevention, 8(1), 27-32

Guruvayoorappan, C. and Kuttan, G. (2008). Methanol extract of Biophytum sensitivum alters the cytokine profile and inhibits iNOS and COX-2 expression in LPS/Con A stimulated macrophages. Drug and Chemical Toxicology, 31(1), 175-188. https:// doi.org/10.1080/01480540701688915

Helal, G.A., Sarhan, M.M., Shahla, A.N.K.A. and ElKhair, E.K.A. (2007). Effects of Cymbopogon citratus L. essential oil on the growth, morphogenesis and aflatoxin production of Aspergillus flavus ML2-strain. Journal of Basic Microbiology, 47(1), 5 - 15. https://doi.org/10.1002/ jobm.200610137 
Inngjerdingen, M., Inngjerdingen, K.T., Patel, T.R., Allen, S., Chen, X., Rolstad, B., Morris, G.A., Harding, S.E., Michaelsen, T.E., Diallo, D. and Paulsen, B.S. (2008). Pectic polysaccharides from Biophytum petersianum Klotzsch, and their activation of macrophages and dendritic cells. Glycobiology, 18(12), 1074-1084. https:// doi.org/10.1093/glycob/cwn090

Joseph, G.S., Jayaprakasha, G.K., Selvi, A.T., Jena, B.S. and Sakariah, K.K. (2005). Antiaflatoxigenic and antioxidant activities of Garcinia extracts. International Journal of Food Microbiology, 101(2), 153-160.

https://doi.org/10.1016/ j.ijfoodmicro.2004.11.001

Kim, J.H., Mahoney, N., Chan, K.L., Molyneux, R. and Campbell, B.C. (2006). Controlling foodcontaminating fungi by targeting antioxidant stressresponse system with natural phenolic compounds. Applied Microbiology and Biotechnology, 70(6), 735 -739. https://doi.org/10.1007/s00253-005-0123-6

Lin, Y.L. and Wang, W.Y. (2003). Chemical constituents of Biophytum sensitivum. Zhong huá yáo xué zázhì, 55(1), 71-75.

Manso, S., Cacho-Nerin, F., Becerril, R. and Nerín, C. (2013). Combined analytical and microbiological tools to study the effect on Aspergillus flavus of cinnamon essential oil contained in food packaging. Food Control, 30(2), 370-378. https:// doi.org/10.1016/j.foodcont.2012.07.018

Marei, G.I.K., Abdel Rasoul, M.A. and Abdelgaleil, S.A.M. (2012). Comparative antifungal activities and biochemical effects of monoterpenes on plant pathogenic fungi. Pesticide Biochemistry and Physiology, 103(1), 56 - 61. https://doi.org/10.1016/ j.pestbp.2012.03.004

Mellon, J.E. and Cotty, P.J. (1998). Effects of oilseed storage proteins on aflatoxin production by Aspergillus flavus. Journal of the American Oil Chemists' Society, 75(12), 1085-1089. https:// doi.org/10.1007/s11746-998-0294-2

Murugan, K., Anandaraj, K. and Al-Sohaibani, S. (2013). Antiaflatoxigenic food additive potential of Murraya koenigii: An in vitro and molecular interaction study. Food Research International, 52 (1), $8-16 . \quad$ https://doi.org/10.1016/ j.foodres.2013.02.001

Natarajan, D., Shivakumar, M.S. and Srinivasan, R. (2010). Antibacterial activity of leaf extracts of Biophytum sensitivum (L.) DC. Journal of Pharmaceutical Sciences and Research, 2(11), 717 720

Prakash, B., Singh, P., Kedia, A. and Dubey, N.K.
(2012). Assessment of some essential oils as food preservatives based on antifungal, anti-aflatoxin, antioxidant activities and in vivo efficacy in food system. Food Research International, 49(1), 201208. https://doi.org/10.1016/j.foodres.2012.08.020

Riba, A., Bouras, N., Mokrane, S., Mathieu, F., Lebrihim, A. and Sabaou, N. (2010). Aspergillus section Flavi and aflatoxins in Algerian wheat and derived products. Food and Chemistry Toxicology, 48(10), 2772-2777. https://doi.org/10.1016/ j.fct.2010.07.005

Samapundo, S., De Meulenaer, B., Osei-Nimoh, D., Lamboni, Y., Debevere, J. and Devlieghere, F. (2007). Can phenolic compounds be used for the protection of corn from fungal invasion and mycotoxin contamination during storage? Food Microbiology, 24(5), 465-473. https:// doi.org/10.1016/j.fm.2006.10.003

Santoso, B., Kilmaskossu, A. and Sambodo, P. (2007). Effects of saponin from Biophytum petersianum Klotzsch on ruminal fermentation, microbial protein synthesis and nitrogen utilization in goats. Animal Feed Science and Technology, 137(1-2), 58-68. https://doi.org/10.1016/j.anifeedsci.2006.10.005

Skočibušić, M., Bezić, N. and Dunkić, V. (2006). Phytochemical composition and antimicrobial activities of the essential oils from Satureja subspicata Vis. growing in Croatia. Food Chemistry, 96(1), $20-28 . \quad$ https://doi.org/10.1016/ j.foodchem.2005.01.051

Shih, C.N. and Marth, E.H. (1974). Some cultural conditions that control biosynthesis of lipid and aflatoxin by Aspergillus parasiticus. Applied Microbiology, 27(3), 452-456.

Sohaibani, S.A., Murugan, K., Lakshimi, G. and Anandraj, K. (2011). Xerophilic aflatoxigenic black tea fungi and their inhibition by Elettaria cardamomum and Syzygium aromaticum extracts. Saudi Journal of Biology Science, 18(4), 387 - 394. https://doi.org/10.1016/j.sjbs.2011.06.005

Syarief, R., La Ega and Nurwitri, C.C. (2012). Food Mycotoxin. $2^{\text {nd }}$ ed. Bogor: IPB Press.

Tataoui-Elaraki, A., Ferhout, H. and Errifi, A. (1993). Inhibition of fungal asexual reproduction stages by three Moroccan essential oils. Journal of Essential Oil Research, 5(5), 535-545. https:// doi.org/10.1080/10412905.1993.9698274

Tian, J., Ban, X., Zeng, H., He, J., Huang, B. and Wang, Y. (2011). Chemical composition and antifungal activity of essential oil from Cicutavirosa L. var. latisecta Celak. International Journal of Food Microbiology, 145(2-3), 464-470. https:// 
doi.org/10.1016/j.jifoodmicro.2011.01.023

Tolouee, M., Alinezhad, S., Saberi, R., Eslamifar, A., Zad, S.J., Jaimand, K., Taeb, J., Mohammad-Bagher, R., Kawachi, M., Shams-Ghahfarokhi, M. and Razzaghi-Abyaneh, M. (2010). Effect of Matricaria chamomilla L. flower essential oil on the growth and ultrastructure of Aspergillus niger van Tieghem. International Journal of Food Microbiology, 139(3), 127-133. https://doi.org/10.1016/ j.ijfoodmicro.2010.03.032

Tzortzakis, N.G. and Economakis, C.D. (2007). Antifungal activity of lemongrass (Cymbopogon citratus L.) essential oil against key postharvest pathogens. Innovative Food Science and Emerging Technologies, 8(2), 253-258. https:// doi.org/10.1016/j.ifset.2007.01.002

Zambonelli, A., D' Aurelio, A.Z., Bianchi, A. and Albasini, A. (1996). Effects of essential oils on phytopathogenic fungi. Journal of Phytopathology, 144(9-10), 491-494. https://doi.org/10.1111/j.14390434.1996.tb00330.x 